Article

\title{
Facet-Dependent Cuprous Oxide Nanocrystals Decorated with Graphene as Durable Photocatalysts under Visible Light
}

\author{
Shou-Heng Liu * and Jun-Sheng Lu \\ Department of Environmental Engineering, National Cheng Kung University, Tainan 70101, Taiwan; \\ dalelu4404@gmail.com \\ * Correspondence: shliu@mail.ncku.edu.tw; Tel.: +886-6-275-7575 (ext. 65843)
}

Received: 25 May 2018; Accepted: 10 June 2018; Published: 11 June 2018

\begin{abstract}
Three morphologies (octahedral, hierarchical and rhombic dodecahedral) of crystal $\mathrm{Cu}_{2} \mathrm{O}$ with different facets $(\{111\},\{111\} /\{110\}$, and $\{110\})$ incorporating graphene sheets (denoted as o- $-\mathrm{Cu}_{2} \mathrm{O}-\mathrm{G}, \mathrm{h}-\mathrm{Cu}_{2} \mathrm{O}-\mathrm{G}$ and $\mathrm{r}-\mathrm{Cu}_{2} \mathrm{O}-\mathrm{G}$, respectively) have been fabricated by using simple solution-phase techniques. Among these photocatalysts, the $r-\mathrm{Cu}_{2} \mathrm{O}-\mathrm{G}$ possesses the best photocatalytic performance of $98 \%$ removal efficiency of methyl orange (MO) with outstanding kinetics for $120 \mathrm{~min}$ of visible light irradiation. This enhancement is mainly due to the dangling " $\mathrm{Cu}$ " atoms in the highly active $\{110\}$ facets, resulting in the increased adsorption of negatively charged MO. More importantly, the unique interfacial structures of $\mathrm{Cu}_{2} \mathrm{O}$ rhombic dodecahedra connected to graphene nanosheets can not only decrease the recombination of electron-hole pairs but also stabilize the crystal structure of $\mathrm{Cu}_{2} \mathrm{O}$, as verified by a series of spectroscopic analyses (e.g., $\mathrm{X}$-ray diffraction (XRD), X-ray photoelectron spectroscopy (XPS), scanning electron microscopy (SEM) and transmission electron microscopy (TEM)). The effective photocatalysts developed in this work could be applied to the efficient decolorization of negatively charged organic dyes by employing solar energy.
\end{abstract}

Keywords: $\mathrm{Cu}_{2} \mathrm{O}$; crystal facets; graphene sheets; photocatalytic degradation; durability

\section{Introduction}

Metal oxide semiconductors have been intensively investigated for photocatalytic degradation of organic pollutants for many years [1-3]. However, these photocatalysts, e.g., $\mathrm{TiO}_{2}$ and $\mathrm{ZnO}$ (band gap $\cong 3.2 \mathrm{eV}$ ), can exhibit superior photocatalysis properties in the ultraviolet (UV) light region, leading to their limited practical application in wastewater treatments due to the restricted use of solar energy [4-8]. Cuprous oxide $\left(\mathrm{Cu}_{2} \mathrm{O}\right)$, which is a p-type semiconductor with a direct band gap of ca. $2.17 \mathrm{eV}$, has been widely studied as an efficient photocatalyst [9-13] because of its abundance, low cost, environmental-friendliness and good visible-light response. Nonetheless, the photocatalytic activity of $\mathrm{Cu}_{2} \mathrm{O}$ is constrained by fast recombination of the electron/hole $(\mathrm{e} / \mathrm{h})$ pairs [14] and has low durability [15]. Therefore, many studies have been dedicated to enhancing visible light-active photocatalysis by enhancing the segregation of electron-hole pairs. For instance, incorporating ions into the semiconductor [16-21], sensitization with dyer and surface complex [22-24], and coupling two or more semiconductors [25,26]. Moreover, well-defined facets of $\mathrm{Cu}_{2} \mathrm{O}$ which exhibit unique crystallographic properties related to different atomic terminated arrangements have been demonstrated to make a great improvement to photocatalysis [27-29]. The $\{110\}$ facets of $\mathrm{Cu}_{2} \mathrm{O}$ were found to have a superior photocatalytic activity toward the degradation of methyl orange [27]. In addition, the $\mathrm{Cu}_{2} \mathrm{O}$ octahedra crystals consisting of $\{111\}$ facets showed higher photocatalytic 
performance as compared to truncated cubic crystals abundant in $\{100\}$ facets which has been attributed to the lower surface energy density of $\{100\}$ facets than that of $\{111\}$ facets [30]. In comparison to the pure $\mathrm{Cu}_{2} \mathrm{O}$ octahedra with $\{111\}$ surfaces and pure cubes with $\{100\}$ surfaces, the combination of 26-facet and 18-facet polyhedra with main $\{110\}$ was observed to have better adsorption and photocatalytic activities [31]. However, the aforementioned $\mathrm{Cu}_{2} \mathrm{O}$ crystals may suffer from the deterioration of their crystal structure during long-term operation [32].

To further increase the stability of $\mathrm{Cu}_{2} \mathrm{O}$ nanocrystals, one of the possible methods was carried out by the incorporation of carbonaceous materials onto $\mathrm{Cu}_{2} \mathrm{O}$ [33-35]. Graphene is a well-known two-dimensional (2D) carbon material [36], which has distinguishing physiochemical properties such as a theoretical surface area $\left(\sim 2965 \mathrm{~m}^{2} \mathrm{~g}^{-1}\right)$ [37], high intrinsic electron mobility $\left(2 \times 10^{5} \mathrm{~cm}^{2} \mathrm{~V}^{-1} \mathrm{~s}^{-1}\right)$ [38], and exceptional chemical durability [39-41]. Owing to these unique properties, visible light-driven photocatalysts based on the synthesis of $\mathrm{Cu}_{2} \mathrm{O}$-graphene composites $[35,42,43]$ for fuel production and pollutant degradation have been proposed. However, limited studies have been reported in terms of different facets of $\mathrm{Cu}_{2} \mathrm{O}$-graphene nanoheterostructures on their visible light-responsive activity and corresponding durability.

In this research, three different morphologies of $\mathrm{Cu}_{2} \mathrm{O}$ crystals with low-index facets $(\{111\}$, $\{111\} /\{110\}$, and $\{110\})$ decorated with graphene sheets were prepared via simple wet-chemical methods. These as-synthesized $\mathrm{Cu}_{2} \mathrm{O}$ crystals were thoroughly characterized by a variety of analytical spectroscopies and used as visible light-driven photocatalysts in the degradation of methyl orange (MO).

\section{Experiment}

\subsection{Photocatalyts Preparation}

Typically, the synthesis of graphene oxide (GO) was carried out by referring to a modified route described earlier [44]. For preparation of octahedral $\mathrm{Cu}_{2} \mathrm{O}$ [27] and octahedral $\mathrm{Cu}_{2} \mathrm{O}$-graphene, ca. $88 \mathrm{~mL}$ of deionized water or $1 \%$ GO solution was mixed with ca. $1 \mathrm{~mL}$ of copper(II) chloride solution and $0.87 \mathrm{~g}$ of sodium dodecyl sulfate (SDS) solids under vigorous stirring until the dissolution of the SDS powder. Then, $8.5 \mathrm{~mL}$ of $0.2 \mathrm{M} \mathrm{NH}{ }_{2} \mathrm{OH} \cdot \mathrm{HCl}$ and $2.5 \mathrm{~mL}$ of $1.0 \mathrm{M} \mathrm{NaOH}$ solution were consecutively added to the resulting mixture. Lastly, the precipitate was treated by centrifugation and dried under a vacuum. The aforementioned photocatalysts prepared by using deionized water and $1 \%$ $\mathrm{GO}$ solution in the synthesis process were labelled as o- $\mathrm{Cu}_{2} \mathrm{O}$ and o- $\mathrm{Cu}_{2} \mathrm{O}-\mathrm{G}$, respectively.

In terms of the synthesis of hierarchical facets of $\mathrm{Cu}_{2} \mathrm{O}$ [30] and hierarchical facets of $\mathrm{Cu}_{2} \mathrm{O}$-graphene, $48 \mathrm{~mL}$ of $1 \%$ GO solution was mixed well with $1 \mathrm{~mL}$ of copper(II) chloride solution. Afterward, $40 \mathrm{~mL}$ of ethylene glycol (EG) was introduced to the aforementioned mixture. Then, $24 \mathrm{~mL}$ of $0.1 \mathrm{M} \mathrm{NH}_{2} \mathrm{OH} \cdot \mathrm{HCl}$ was added to the above solution for $10 \mathrm{~min}$. The resultant solution was moved to a Teflon-lined stainless steel autoclave, followed by ramping from room temperature to $180{ }^{\circ} \mathrm{C}$ for $1 \mathrm{~h}$. The solid products were filtrated, washed and dried at ambient temperature. The aforementioned samples prepared without and with $1 \%$ GO solution in the synthesis process were denoted as h-Cu and $\mathrm{h}-\mathrm{Cu}_{2} \mathrm{O}-\mathrm{G}$, respectively.

For the preparation of rhombic dodecahedral $\mathrm{Cu}_{2} \mathrm{O}$ [27] and rhombic dodecahedral $\mathrm{Cu}_{2} \mathrm{O}$-graphene, ca. $34.6 \mathrm{~mL}$ of deionized water or $1 \% \mathrm{GO}$ solution was heated to $34{ }^{\circ} \mathrm{C}$ in a water bath. Then, ca. $2.5 \mathrm{~mL}$ of copper(II) chloride solution $(0.1 \mathrm{M})$ and $0.44 \mathrm{~g}$ of SDS solids were added into the above mixture with continuous stirring. While the SDS was dissolved, $2.5 \mathrm{~mL}$ of $\mathrm{NaOH}$ solution was introduced, followed by adding $12 \mathrm{~mL}$ of $0.1 \mathrm{M} \mathrm{NH} \mathrm{H}_{2} \mathrm{OH} \cdot \mathrm{HCl}$ to the resulting mixture. Finally, the precipitated products were separated by centrifuge, washed by using a water-ethanol mixture and dried. The aforementioned samples prepared by using deionized water and 1\% GO solution in the synthesis process were denoted as $\mathrm{r}-\mathrm{Cu}_{2} \mathrm{O}$ and $\mathrm{r}-\mathrm{Cu}_{2} \mathrm{O}-\mathrm{G}$, respectively. 


\subsection{Characterizations of Photocatalyts}

Powder X-ray diffraction (XRD) patterns of the samples were examined by using a PANalytical $\mathrm{X}^{\prime}$ Pert PRO diffractometer with $\mathrm{Cu} \mathrm{K} \alpha$ radiation $(\lambda=1.541 \AA)$. The elemental compositions of samples were analysed by X-ray photoelectron spectroscopy (XPS) using a Kratos AXIS Ultra DLD spectrometer (Kratos Analytical Ltd., Stretford, Manchester, UK) and monochromated Al K $\alpha$ $\mathrm{X}$-ray source. The morphologies of the photocatlysts were observed through a scanning electron microscope (SEM, JEOL-7000F, JEOL Ltd., Akishima, Tokyo, Japan) with an accelerating voltage of $20 \mathrm{kV}$. In addition, to further study the detailed surface characteristics of the $\mathrm{Cu}_{2} \mathrm{O}$ nanocrystals, a high-resolution transmission electron microscopy (TEM, JEOL 2100F, JEOL Ltd., Akishima, Tokyo, Japan) was carried out. The UV-visible (UV-Vis) diffuse reflection spectra of the samples were collected on a UV-Vis spectrophotometer (Varian, Cary 100, Palo Alto, CA, USA).

\subsection{Photocatalytic Degradation of Organic Pollutants}

Photocatalytic degradation tests of MO were performed at $25{ }^{\circ} \mathrm{C}$ in a photoreactor $(100 \mathrm{~mL})$ described previously [35]. The test solution was prepared via mixing $5.0 \mathrm{mg}$ of photocatalysts into $80 \mathrm{~mL}$ of $\mathrm{MO}$ solution $\left(15 \mathrm{mg} \mathrm{L}^{-1}\right)$. Prior to irradiation, the aqueous solution was kept stirring in the dark for $2 \mathrm{~h}$ to establish the adsorption equilibrium. The $\mathrm{pH}$ value of the solution was 5.6. Then, the photocatalytic reaction was performed by using a $300 \mathrm{~W}$ Xe lamp combined with a $420 \mathrm{~nm}$ cutoff filter as the light source. About $2 \mathrm{~mL}$ of aliquots was periodically withdrawn for every $30 \mathrm{~min}$, centrifuged to separate solid samples, and the variations of concentration were measured by using a Hitachi UV-Visible (UV-Vis) spectroscope (Model U-2910).

\section{Results and Discussion}

As displayed in Figure 1, the XRD patterns of various shapes of $\mathrm{Cu}_{2} \mathrm{O}$ - and $\mathrm{Cu}_{2} \mathrm{O}$-incorporated graphene samples possess five characteristic reflections at $2 \theta=29.6^{\circ}, 36.4^{\circ}, 42.3^{\circ}, 61.4^{\circ}$ and $73.6^{\circ}$ which are attributed to the (110), (111), (200), (220), (311) planes of cuprous oxide. This result shows the synthesized samples are classified to the cubic phase $\mathrm{Cu}_{2} \mathrm{O}$ (JCPDS No. 78-2076). The sharp diffraction peaks indicate that the high crystallinity of $\mathrm{Cu}_{2} \mathrm{O}$ with different morphologies in all samples can be prepared by using wet-chemical methods. In the previous study [27], the intensity of the (220) peak to that of the (200) peak $\left(I_{(220)} / I_{(200)}\right)$ is able to be used to evaluate the degree of crystal structure. For instance, the index of $I_{(220)} / I_{(200)}$ is nearly 0.79 in terms of rhombic dodecahedra $\mathrm{Cu}_{2} \mathrm{O}$. As can be seen in Figure 1, while incorporating graphene onto various crystals of $\mathrm{Cu}_{2} \mathrm{O}\left(\mathrm{o}-\mathrm{Cu}_{2} \mathrm{O}-\mathrm{G}\right.$, h- $\mathrm{Cu}_{2} \mathrm{O}-\mathrm{G}$ and $\left.\mathrm{r}-\mathrm{Cu}_{2} \mathrm{O}-\mathrm{G}\right)$, the value of $\mathrm{I}_{(220)} / \mathrm{I}_{(200)}$ is practically unchanged, indicating that no apparent perturbation of crystal structure is observed. This result implies that the introduction of graphene may cause little impact on the growth of nanocrystal $\mathrm{Cu}_{2} \mathrm{O}$ in the samples.

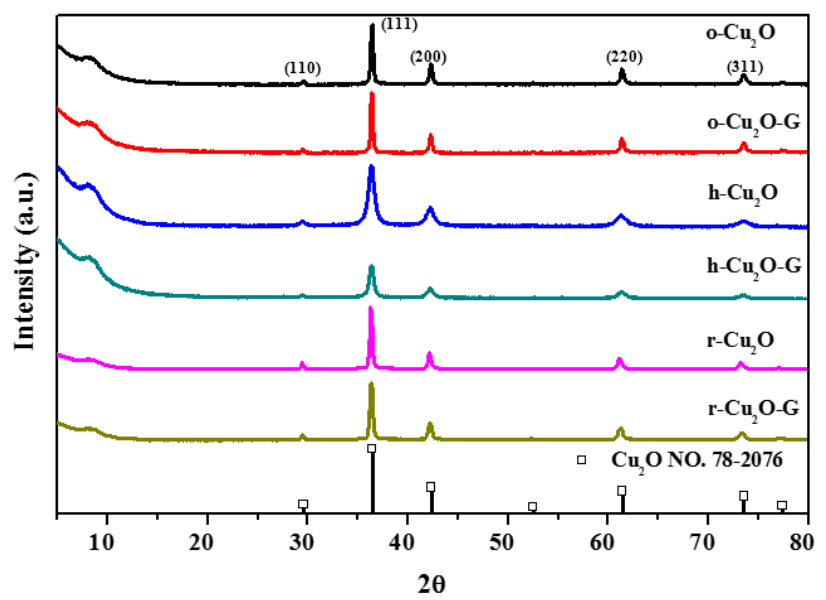

Figure 1. X-ray diffraction (XRD) patterns of different photocatalysts. 
The morphologies of the crystal $\mathrm{Cu}_{2} \mathrm{O}, \mathrm{o}-\mathrm{Cu}_{2} \mathrm{O}-\mathrm{G}, \mathrm{h}-\mathrm{Cu}_{2} \mathrm{O}-\mathrm{G}$ and $\mathrm{r}-\mathrm{Cu}_{2} \mathrm{O}-\mathrm{G}$ were investigated by using field emission scanning electron microscopy (FESEM). As can be seen in Figure 2a, the pristine $\mathrm{o}-\mathrm{Cu}_{2} \mathrm{O}$ possesses octahedron morphology of eight $\{111\}$ facets. Figure $2 \mathrm{~b}$ presents the typical image of the microspherical h- $\mathrm{Cu}_{2} \mathrm{O}$ with randomly crosslinked polyhedrons which are composed of $\{110\}$ and $\{111\}$ facets. In terms of $\mathrm{r}-\mathrm{Cu}_{2} \mathrm{O}$, a 12-facet polyhedral with mostly $\{110\}$ facets can be observed, as displayed in Figure 2c. Based on the center of the Gaussian distribution, the particle sizes of o- $\mathrm{Cu}_{2} \mathrm{O}-\mathrm{G}$, $\mathrm{h}-\mathrm{Cu}_{2} \mathrm{O}-\mathrm{G}$ and $\mathrm{r}-\mathrm{Cu}_{2} \mathrm{O}-\mathrm{G}$ are calculated to be $315 \pm 35,218 \pm 19$ and $289 \pm 38 \mathrm{~nm}$, respectively. Upon incorporating graphene onto various crystals of $\mathrm{Cu}_{2} \mathrm{O}\left(\mathrm{o}-\mathrm{Cu}_{2} \mathrm{O}-\mathrm{G}, \mathrm{h}-\mathrm{Cu}_{2} \mathrm{O}-\mathrm{G}\right.$ and $\left.r-\mathrm{Cu}_{2} \mathrm{O}-\mathrm{G}\right)$, the morphologies and crystal structure $\mathrm{Cu}_{2} \mathrm{O}$ are almost the same as those without graphene, as shown in Figure 2c-e. The microstructures of the $\mathrm{Cu}_{2} \mathrm{O}$ nanocrystals were additionally identified by TEM. It can be observed that the TEM images (Figure 3) show that crystal $\mathrm{Cu}_{2} \mathrm{O}$ is incorporating with the wrinkled, thin and transparent graphene nanosheets. The high-resolution TEM (HRTEM) images of $\mathrm{o}-\mathrm{Cu}_{2} \mathrm{O}-\mathrm{G}, \mathrm{h}-\mathrm{Cu}_{2} \mathrm{O}-\mathrm{G}$ and $\mathrm{r}-\mathrm{Cu}_{2} \mathrm{O}-\mathrm{G}$ in Figure $3 \mathrm{~d}-\mathrm{f}$ show that the interplanar lattice with d-spacings of 0.24 and $0.30 \mathrm{~nm}$ are, respectively, assigned to the (111) and (110) planes of $\mathrm{Cu}_{2} \mathrm{O}$. Moreover, selected area electron diffraction (SAED) and HRTEM suggest that these crystal $\mathrm{Cu}_{2} \mathrm{O}$ samples possess a single-crystal structure, which matches well with the high crystallinity explored by XRD. Therefore, different shapes of highly crystallized $\mathrm{Cu}_{2} \mathrm{O}$ decorated with graphene nanosheets have been fabricated by using simple wet-chemical methods.

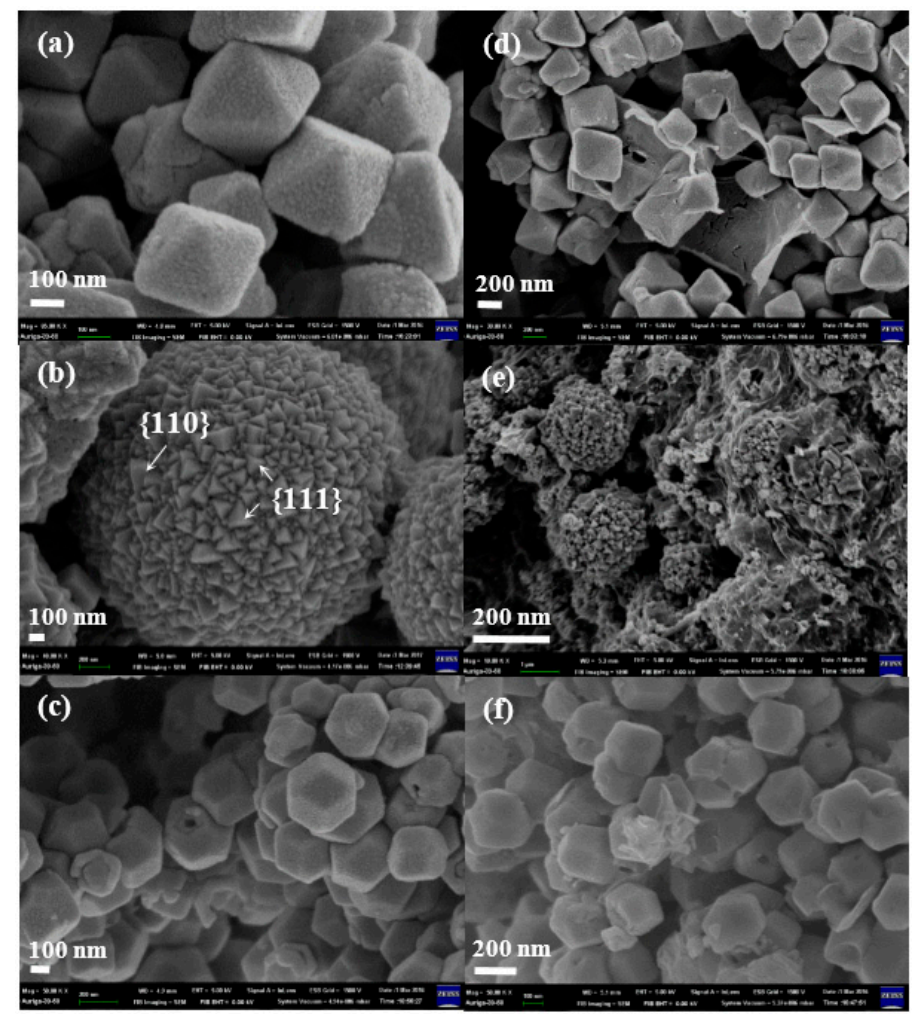

Figure 2. Scanning electron microscope (SEM) images of (a) o- $\mathrm{Cu}_{2} \mathrm{O}$; (b) h- $\mathrm{Cu}_{2} \mathrm{O}$; (c) $\mathrm{r}-\mathrm{Cu}_{2} \mathrm{O}$; (d) o- $\mathrm{Cu}_{2} \mathrm{O}-\mathrm{G}$; (e) h-Cu $2 \mathrm{O}-\mathrm{G}$ and (f) $\mathrm{r}-\mathrm{Cu}_{2} \mathrm{O}-\mathrm{G}$. 


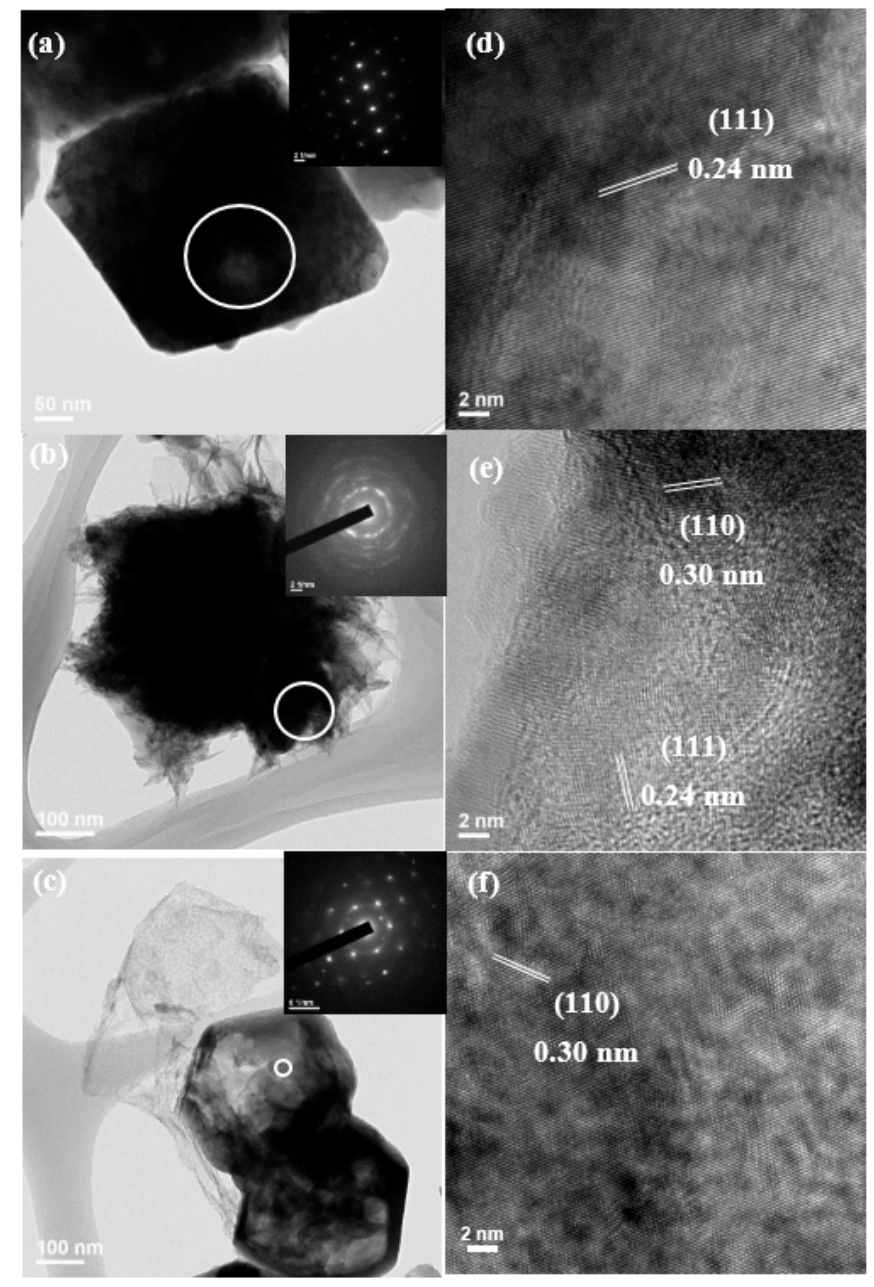

Figure 3. Transmission electron microscope (TEM) images of (a) o- $\mathrm{Cu}_{2} \mathrm{O}-\mathrm{G} ;(\mathbf{b}) \mathrm{h}-\mathrm{Cu}_{2} \mathrm{O}-\mathrm{G}$; (c) r- $\mathrm{Cu}_{2} \mathrm{O}-\mathrm{G}$ and high-resolution TEM (HRTEM) of (d) o- $\mathrm{Cu}_{2} \mathrm{O}-\mathrm{G}$; (e) h- $\mathrm{Cu}_{2} \mathrm{O}-\mathrm{G}$; (f) $\mathrm{r}-\mathrm{Cu}_{2} \mathrm{O}-\mathrm{G}$. Inset: selected area electron diffraction (SAED) from the circle area.

The surface atomic compositions and interfacial electronic states of the samples can be investigated by XPS analysis, as displayed in Figure 4. The peaks at 284.6, 286.5 and $288.4 \mathrm{eV}$ in the C1s spectra (Figure 4a) are assigned to non-oxygenated, epoxy/hydroxyl and carboxyl carbons, respectively [45,46]. The intensities observed for the peaks at 286.5 and $288.4 \mathrm{eV}$ in the o- $\mathrm{Cu}_{2} \mathrm{O}-\mathrm{G}, \mathrm{h}-\mathrm{Cu}_{2} \mathrm{O}-\mathrm{G}$ and $\mathrm{r}-\mathrm{Cu} \mathrm{u}_{2} \mathrm{O}-\mathrm{G}$ samples are decreased slightly in comparison to the pure graphene oxide sheets, suggesting that the graphene sheets may maintain the reduced states even with the existence of $\mathrm{Cu}_{2} \mathrm{O}$ nanocrystals in the samples. The XPS of spectra of Cu2p (Figure $4 \mathrm{~b}$ ) indicate the photocatalysts have the principal and satellite features at ca. $934 \mathrm{eV}$ and $944 \mathrm{eV}$ which are attributed to $\mathrm{Cu}(\mathrm{II})$, while the features at ca. 932 and $952 \mathrm{eV}$ are assigned to $\mathrm{Cu}(\mathrm{I}) 2 \mathrm{p}_{3 / 2}$ and $\mathrm{Cu}(\mathrm{I}) 2 \mathrm{p}_{1 / 2}$ peaks [9], respectively. In addition, the O1s (see Figure 4c) peaks at ca. 532.5 and $530.3 \mathrm{eV}$ are assigned to $\mathrm{C}-\mathrm{O}$ and $\mathrm{Cu}-\mathrm{O}$ bindings, respectively. As a result, the contents of copper(I) for o- $\mathrm{Cu}_{2} \mathrm{O}-\mathrm{G}$ and $\mathrm{r}-\mathrm{Cu}_{2} \mathrm{O}-\mathrm{G}$ composites are much higher, indicating that $\mathrm{Cu}_{2} \mathrm{O}$ nanoparticles may exist stably when dispersed on graphene nanosheets, which can maintain the photocatalytic performance during photodegradation process [47]. Moreover, it is hard to attain bulk information of the atoms by using XPS because a small number of atomic layers on the surface are identified. In addition, it is noteworthy that the diffraction features of copper oxide could hardly be found for all photocatalysts by using the XRD, which is possibly because of the identification of the crystal structure in the bulk phase (see Figure 1). 

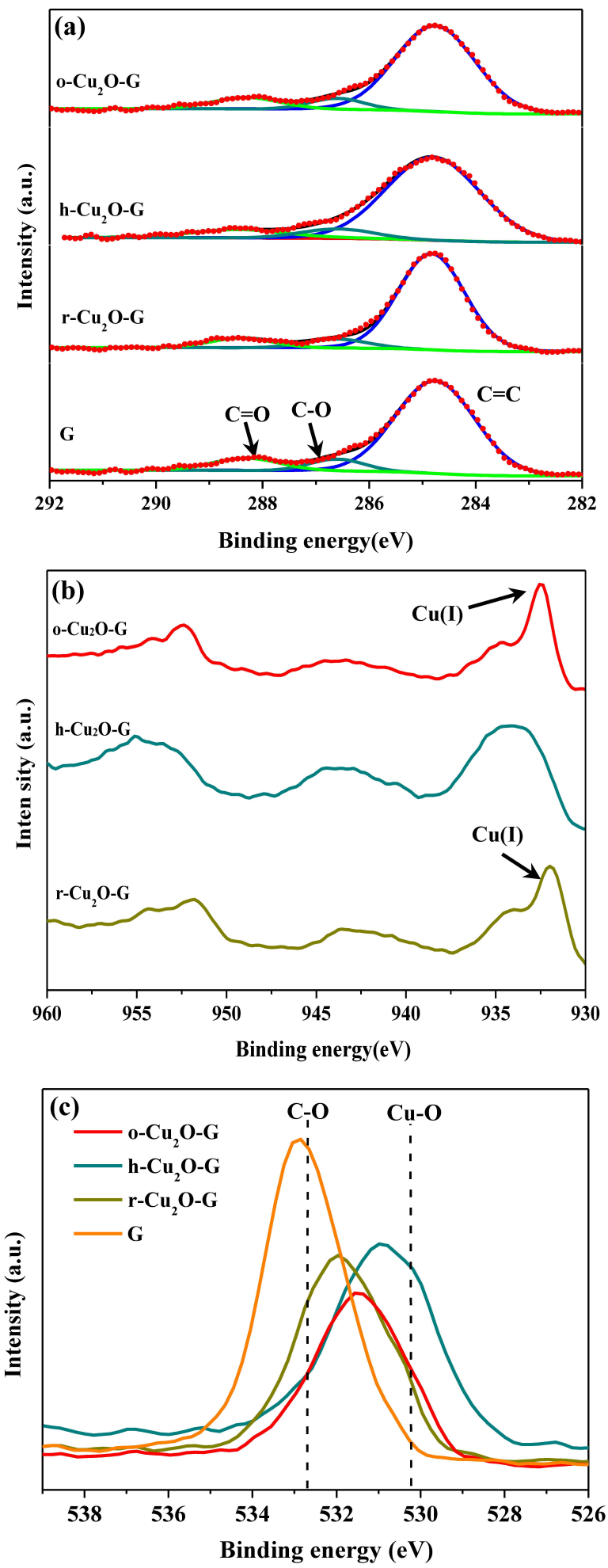

Figure 4. X-ray photoelectron spectroscopy (XPS) spectra of different photocatalysts at the (a) high-resolution C 1s core-level; (b) Cu 2p core-level; and (c) O 1s core-level.

To understand the optical properties of o- $\mathrm{Cu}_{2} \mathrm{O}-\mathrm{G}, \mathrm{h}-\mathrm{Cu}_{2} \mathrm{O}-\mathrm{G}$ and $\mathrm{r}-\mathrm{Cu}_{2} \mathrm{O}-\mathrm{G}$ nanocomposites, diffused reflectance UV-Vis (DR UV-Vis) absorption spectroscopies were carried out. Figure 5a shows that $\mathrm{o}-\mathrm{Cu}_{2} \mathrm{O}-\mathrm{G}$ possesses a band edge of ca. $580 \mathrm{~nm}$ in the visible region, suggesting that o-Cu $\mathrm{u}_{2} \mathrm{O}-\mathrm{G}$ photocatalysts having the bandgap of ca. $2.2 \mathrm{eV}$ (see Figure $5 \mathrm{~b}$ ) should be a visible light-sensitive 
semiconductor. However, the $\mathrm{r}-\mathrm{Cu}_{2} \mathrm{O}-\mathrm{G}$ photocatalysts show slightly increased absorbance intensities in the visible-light region (400-800 nm) and absorption edge positions as compared to o- $\mathrm{Cu}_{2} \mathrm{O}-\mathrm{G}$ and $\mathrm{h}-\mathrm{Cu}_{2} \mathrm{O}-\mathrm{G}$. Moreover, the band gap of these photocatalysts can be obtained by plotting transformed Kubelka-Munk functions, as illustrated in Figure 5b. The band gaps of o- $\mathrm{Cu}_{2} \mathrm{O}-\mathrm{G}, \mathrm{h}-\mathrm{Cu}_{2} \mathrm{O}-\mathrm{G}$ and $\mathrm{r}-\mathrm{Cu}_{2} \mathrm{O}-\mathrm{G}$ photocatalysts are ca. 2.20, 2.12 and $2.06 \mathrm{eV}$, respectively. This finding may be due to their different crystal sizes and distinct exposed facets in the photocatalysts. Combining the outcomes of the XRD, TEM, SEM, XPS and DR UV-Vis spectra, various morphologies of crystal $\mathrm{Cu}_{2} \mathrm{O}$ incorporated with graphene nanosheets may be able to take advantage of natural light for decontamination and also be recycled for reuse after photocatalytic reactions.
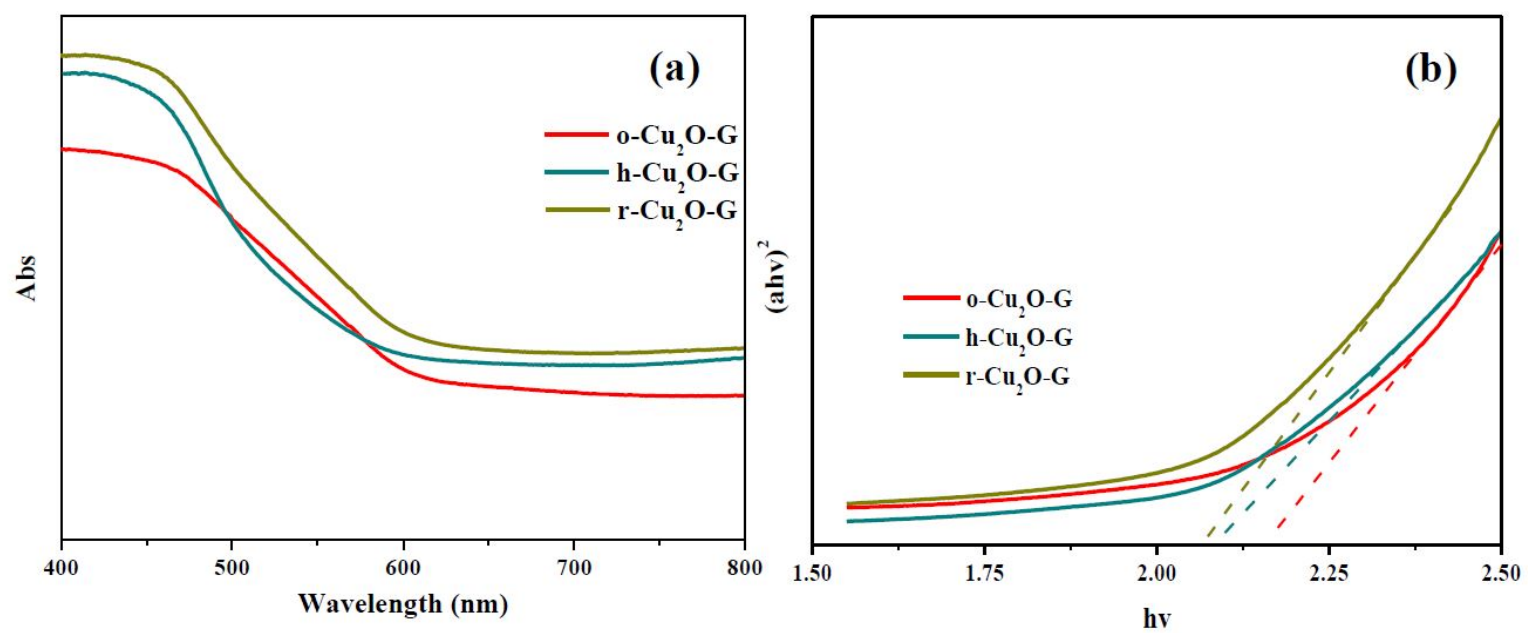

Figure 5. (a) Ultraviolet-visible (UV-Vis) absorption spectra for different samples and (b) the corresponding Kubelka-Munk plots of photocatalysts.

The photocatalytic performance of pure cuprous oxides $\left(\mathrm{o}-\mathrm{Cu}_{2} \mathrm{O}, \mathrm{h}-\mathrm{Cu}_{2} \mathrm{O}\right.$ and $\left.\mathrm{r}-\mathrm{Cu}_{2} \mathrm{O}\right)$ and various graphene-incorporated cuprous oxides $\left(\mathrm{o}-\mathrm{Cu}_{2} \mathrm{O}-\mathrm{G}, \mathrm{h}-\mathrm{Cu}_{2} \mathrm{O}-\mathrm{G}\right.$ and $\left.\mathrm{r}-\mathrm{Cu} \mathrm{u}_{2} \mathrm{O}-\mathrm{G}\right)$ were studied by the photocatalytic oxidation of the $\mathrm{MO}$ solution under visible light illumination at room temperature. About 8.3, 4.5, 17.7, 21.2, 37.4 and 20.2\% of $\mathrm{MO}$ were adsorbed by o- $\mathrm{Cu}_{2} \mathrm{O}$, h- $\mathrm{Cu}_{2} \mathrm{O}, \mathrm{r}-\mathrm{Cu}_{2} \mathrm{O}, \mathrm{o}-\mathrm{Cu} \mathrm{u}_{2} \mathrm{O}-\mathrm{G}$, $\mathrm{h}-\mathrm{Cu}_{2} \mathrm{O}-\mathrm{G}$ and $\mathrm{r}-\mathrm{Cu}_{2} \mathrm{O}-\mathrm{G}$ after $120 \mathrm{~min}$ in the dark, respectively, indicating that the presence of a high surface area of graphene can increase $\mathrm{MO}$ adsorption. Figure 6a shows the concentration variations of $\mathrm{MO}$ as a function of irradiation time. It can be seen that little photocatalytic degradation of $\mathrm{MO}$ on the graphene is apparent. The order of $\mathrm{MO}$ photodegradation ratios of $\mathrm{r}-\mathrm{Cu} 2 \mathrm{O}(79.4 \%)>\mathrm{h}-\mathrm{Cu} 2 \mathrm{O}$ $(35.4 \%)>\mathrm{o}-\mathrm{Cu}_{2} \mathrm{O}(26.9 \%)$ can be observed after $120 \mathrm{~min}$ of visible light irradiation. Based on this result, it is concluded that the rhombic dodecahedra $\mathrm{Cu}_{2} \mathrm{O}$ nanocrystals which expose mainly $\{110\}$ facets exhibit superior photocatalytic activity. However, the octahedral $\mathrm{Cu}_{2} \mathrm{O}$ composed of $\{111\}$ facets have the lowest photocatalytic activity. The hierarchical facets of $\mathrm{Cu}_{2} \mathrm{O}$ exposing both $\{110\}$ and $\{111\}$ facets possess moderate photodegradation activity. Upon the incorporation of graphene sheets onto the aforementioned $\mathrm{Cu}_{2} \mathrm{O}$ crystals, all the photoactivities of prepared catalysts are highly enhanced, suggesting that the existence of graphene owing to the unique interface contact between $\mathrm{Cu}_{2} \mathrm{O}$ facets and graphene [48] can enhance the photocatalytic efficiency. Among them, ca. 98\% photodegradation of $\mathrm{MO}$ can be observed for the $\mathrm{r}-\mathrm{Cu}_{2} \mathrm{O}-\mathrm{G}$ photocatalysts. It has been reported that the level of conduction band (CB) potential for $\mathrm{Cu}_{2} \mathrm{O}(-3.0 \mathrm{eV}$ vs. vacuum) [48] was greater than the level of lowest unoccupied molecular orbital (LUMO) for $\mathrm{MO}$ (-3.3 eV vs. vacuum) [49]. As a result, the electron transfer from the excited $\mathrm{MO}$ to the $\mathrm{Cu}_{2} \mathrm{O}$ can barely happen, i.e., the $\mathrm{MO}$ sensitization during photocatalysis should hardly occur. Moreover, kinetic studies can be used to confirm the photocatalytic activities of various catalysts. As can be seen in Figure $6 \mathrm{~b}$, the photocatalytic reactions follow pseudo-first order kinetics and the corresponding data for rate constants $(\mathrm{k})$ can be attained. Consequently, the $\mathrm{k}$ values of $\mathrm{o}-\mathrm{Cu}_{2} \mathrm{O}, \mathrm{h}-\mathrm{Cu}_{2} \mathrm{O}, \mathrm{r}-\mathrm{Cu}_{2} \mathrm{O}, \mathrm{o}-\mathrm{Cu}_{2} \mathrm{O}-\mathrm{G}, \mathrm{h}-\mathrm{Cu}_{2} \mathrm{O}-\mathrm{G}$ and $\mathrm{r}-\mathrm{Cu} \mathrm{u}_{2} \mathrm{O}-\mathrm{G}$ are found 
to be ca. $0.0026,0.0036,0.0131,0.0043,0.0089$ and $0.0292 \mathrm{~min}^{-1}$, respectively. It should be noted that the photodegradation rate of $\mathrm{r}-\mathrm{Cu}_{2} \mathrm{O}-\mathrm{G}$ is 6.8 and 3.3 times higher than those of o- $\mathrm{Cu}_{2} \mathrm{O}-\mathrm{G}$ and $\mathrm{h}-\mathrm{Cu}_{2} \mathrm{O}-\mathrm{G}$, respectively.
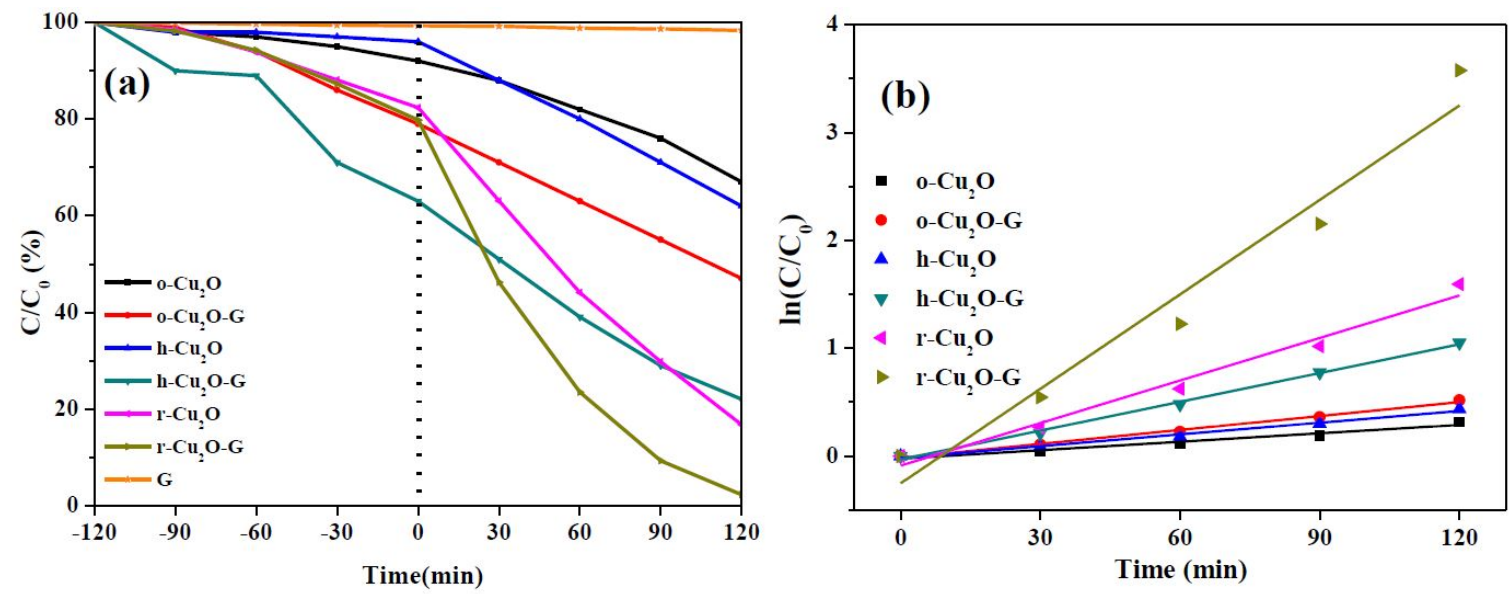

Figure 6. (a) Relative concentration of methyl orange (MO) versus time by various photocatalysts under visible light and (b) kinetic plots from the data in (a).

It is crucial to explore the durability and reusability in terms of practical applications of these photocatalysts. We take $\mathrm{r}-\mathrm{Cu}_{2} \mathrm{O}$ and $\mathrm{r}-\mathrm{Cu}_{2} \mathrm{O}-\mathrm{G}$ as the example photocatalysts to test the stability of $\mathrm{MO}$ degradation. As can be seen in Figure 7a, an obvious decrease of photocatalytic performance (ca. 54.8\%, i.e., from 80.0 to $25.2 \%$ ) can be found for $\mathrm{r}-\mathrm{Cu}_{2} \mathrm{O}$ after three consecutive tests. However, only ca. $10 \%$ of efficiency decline has been observed for $\mathrm{r}-\mathrm{Cu}_{2} \mathrm{O}-\mathrm{G}$, which is probably due to the assistance of graphene. It is noteworthy that no obvious dissimilarity can be found in the fresh and used $\mathrm{r}-\mathrm{Cu}_{2} \mathrm{O}-\mathrm{G}$ photocatalysts (see XRD patterns in Figure $7 \mathrm{~b}$ ) in which $\mathrm{Cu}_{2} \mathrm{O}$ is still the dominant species. The slight decline of catalytic performance in the $\mathrm{r}-\mathrm{Cu}_{2} \mathrm{O}-\mathrm{G}$ photocatalysts may be due to the occurrence of intermediates [46] during photoreaction. It should be noted that the synthesized $r-\mathrm{Cu}_{2} \mathrm{O}-\mathrm{G}$ photocatalysts can perform the photodegradation of $\mathrm{MO}$ with the highest kinetic rate (degradation efficiency = ca. $98 \%$ within $120 \mathrm{~min})$ upon the presence of ultra-low content of samples $\left(0.06 \mathrm{~g} \mathrm{~L}^{-1}\right)$ using visible light illumination. Moreover, these $r-\mathrm{Cu}_{2} \mathrm{O}-\mathrm{G}$ photocatalysts can be obtained via a facile and low-cost liquid-phase method. Above all, our $\mathrm{r}-\mathrm{Cu}_{2} \mathrm{O}-\mathrm{G}$ nanocomposites also have a remarkable enhancement of their long-term durability by the assistance of $1 \mathrm{wt} \%$ of graphene. In comparison to previously reported $\mathrm{Cu}_{2} \mathrm{O}$-based photocatalysts, the synthesized $\mathrm{r}-\mathrm{Cu}_{2} \mathrm{O}-\mathrm{G}$ photocatalysts with dominant $\{110\}$ facets of crystal $\mathrm{Cu}_{2} \mathrm{O}$ exhibit an excellent degradation kinetic in a low concentration of photocatalysts under visible-light irradiation that could be practically used to make the best use of daylight for the remediation of organic wastewater. 

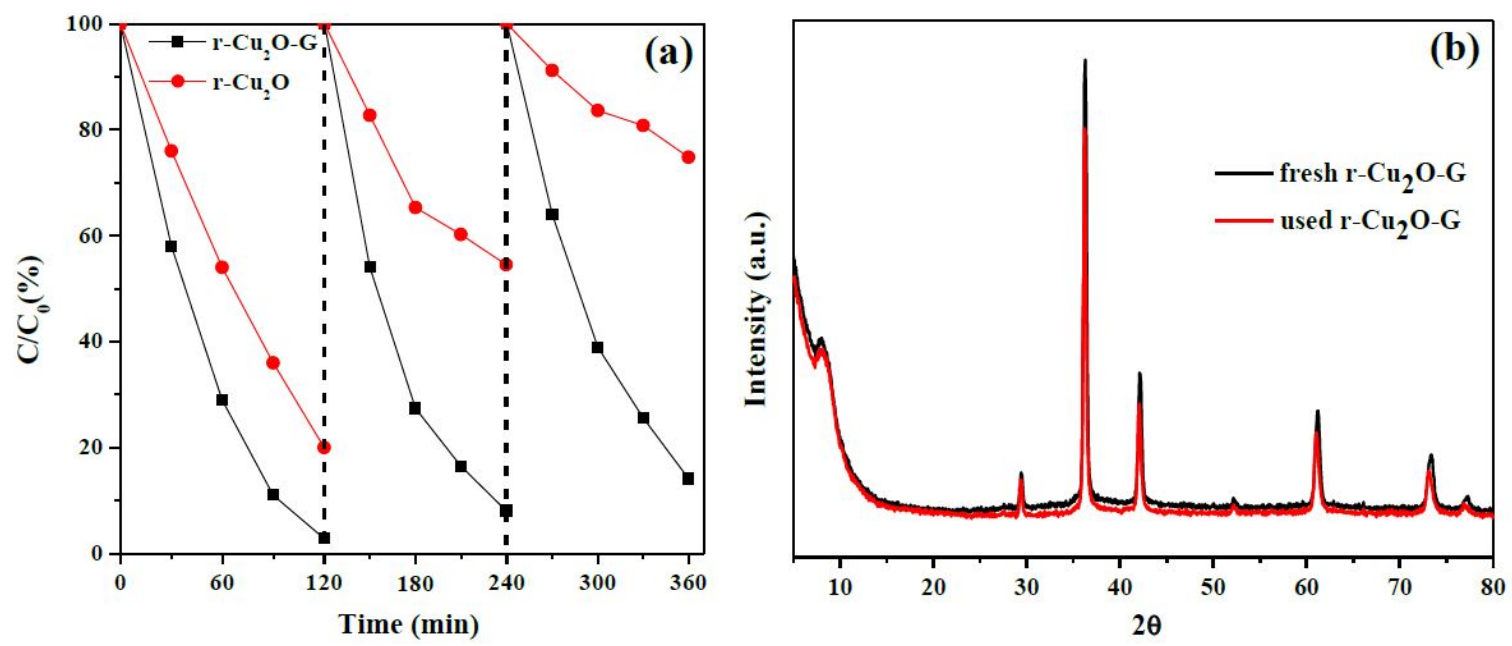

Figure 7. (a) Cyclic tests of $\mathrm{r}-\mathrm{Cu}_{2} \mathrm{O}$ and $\mathrm{r}-\mathrm{Cu}_{2} \mathrm{O}-\mathrm{G}$ photocatalysts for $\mathrm{MO}$ photodegradation under visible light; (b) XRD patterns of the fresh and used $\mathrm{r}-\mathrm{Cu}_{2} \mathrm{O}-\mathrm{G}$.

As shown in Figure 8, according to the aforementioned results a probable mechanism for $\mathrm{MO}$ degradation by crystal $\mathrm{Cu}_{2} \mathrm{O}$-graphene photocatalysts can be proposed. Upon visible-light illumination, the crystal $\mathrm{Cu}_{2} \mathrm{O}$ (e.g., rhombic dodecahedra $\mathrm{Cu}_{2} \mathrm{O}$ ) is excited to produce electrons (in the conduction band (CB)) and holes (in the valence band (VB)). Because of the stronger contact between crystal facets and the graphene surface, the photogenerated electrons can be rapidly transported to the graphene nanosheets. As a consequence of the small difference between the Fermi potential of graphene and the reduction potential of $\mathrm{O}_{2} / \mathrm{O}_{2}{ }^{-}$[50], $\mathrm{O}_{2}{ }^{-}$and $\mathrm{H}_{2} \mathrm{O}_{2}$ can be observed after the reaction of high-energy electrons with the dissolved oxygen. In this way, the recombination of electron/hole pairs can be greatly prohibited. In addition, compared to octahedral $\mathrm{Cu}_{2} \mathrm{O}$ (mainly $\{111\}$ facets), the holes $\left(\mathrm{h}^{+}\right)$with positive charge generated on the valence band (ca. $1.92 \mathrm{eV}$ vs. normal hydrogen electrode (NHE)) of rhombic dodecahedra $\mathrm{Cu}_{2} \mathrm{O}$ (mainly $\{110\}$ facets) also can degrade more $\mathrm{MO}$ molecules (ca. $1.48 \mathrm{eV}$ vs. NHE) [51,52] since the number of dangling $\mathrm{Cu}$ atoms on the $\{110\}$ plane per unit surface area was nearly 1.5 times higher than that on the $\{111\}$ plane, resulting in a more positively charged surface on $\{110\}$ facets [28]. Therefore, the superoxide radical anions, hydrogen peroxide and $\mathrm{h}^{+}$may be the dominant species governing the photodegradation of $\mathrm{MO}$ under visible-light irradiation. It should be noted that the graphene sheets not only serve as acceptors of the photogenerated electrons from $\mathrm{Cu}_{2} \mathrm{O}$ but also as stabilizers to prevent the crystal $\mathrm{Cu}_{2} \mathrm{O}$ from structural destruction under irradiation over a long period.

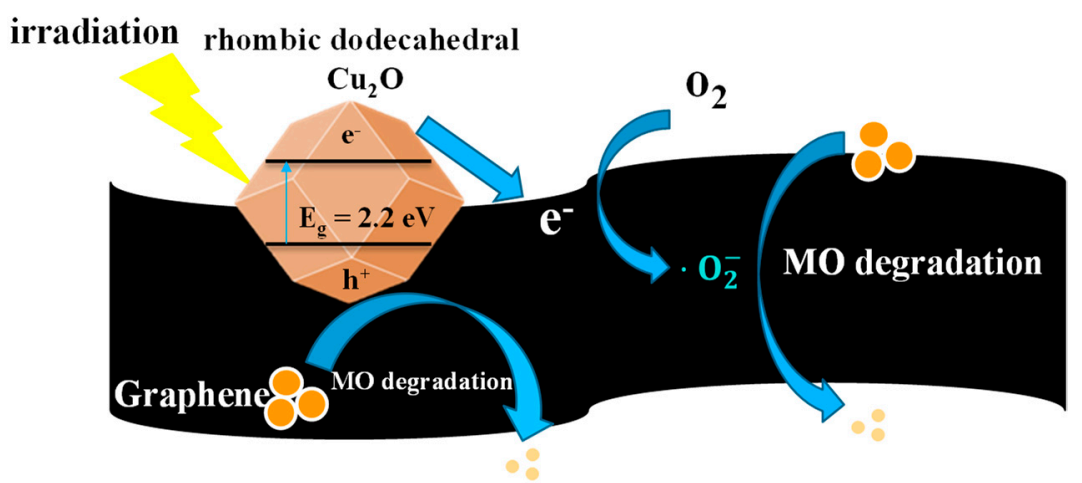

Figure 8. Possible mechanism of $\mathrm{MO}$ photodegradation over $\mathrm{r}-\mathrm{Cu}_{2} \mathrm{O}-\mathrm{G}$ under visible-light illumination. 


\section{Conclusions}

In this study, three different crystal facets of $\mathrm{Cu}_{2} \mathrm{O}$ photocatalysts decorated with graphene sheets were synthesized by using simple solution-phase methods. The order in terms of photocatalytic MO degradation was observed to be as follows: rhombic dodecahedral $\mathrm{Cu}_{2} \mathrm{O}$-graphene $\left(\mathrm{r}-\mathrm{Cu}{ }_{2} \mathrm{O}-\mathrm{G}\right)$ $>$ hierarchical $\mathrm{Cu}_{2} \mathrm{O}$-graphene $\left(\mathrm{h}-\mathrm{Cu}_{2} \mathrm{O}-\mathrm{G}\right)>$ octahedral $\mathrm{Cu}_{2} \mathrm{O}$-graphene $\left(\mathrm{o}-\mathrm{Cu}_{2} \mathrm{O}-\mathrm{G}\right)$, which was demonstrated to be related to the morphologies and crystal structure of facets (i.e., the $\{110\}$ facets are most active toward $\mathrm{MO}$ degradation). In earlier reports regarding $\mathrm{Cu}_{2} \mathrm{O}$-based photocatalysts, the $\mathrm{r}-\mathrm{Cu}_{2} \mathrm{O}-\mathrm{G}$ photocatalysts possessed high kinetics of photocatalytic degradation, i.e., by using an ultra-low content of samples $\left(0.06 \mathrm{~g} \mathrm{~L}^{-1}\right)$ to reach $98 \%$ of $\mathrm{MO}$ photodegradation under $120 \mathrm{~min}$ irradiation of visible light. More importantly, the cycling tests indicate that the resulting r-Cu $2 \mathrm{O}-\mathrm{G}$ composites show a surpassing durability compared to pure $\mathrm{r}-\mathrm{Cu}_{2} \mathrm{O}$ nanocrystals. These significant enhancements are possibly because of the unique interfacial interaction of rhombic dodecahedra $\mathrm{Cu}_{2} \mathrm{O}$ (more positively charged $\{110\}$ facets) with the graphene nanosheets, which could lead to the effective isolation of electron/hole pairs, stabilization of the crystal $\mathrm{Cu}_{2} \mathrm{O}$, and an increase of $\mathrm{MO}$ adsorption. Consequently, the development of a cost-effective and facile method to prepare r- $\mathrm{Cu}_{2} \mathrm{O}-\mathrm{G}$ composites with mostly $\{110\}$ facets and graphene sheets, which exhibit superior photocatalytic performance (kinetics and stability), offers the potential for a promising application in the treatment of organic wastewater by utilizing natural sunlight.

Author Contributions: The design, writing, review and editing of the paper were undertaken by S.-H.L.; the experiments and analysis of the data were undertaken by J.-S.L. Both authors reviewed and approved the manuscript.

Funding: The work was financially supported by Ministry of Science and Technology of Taiwan (MOST 105-2221-E-006-015-MY5).

Conflicts of Interest: The authors declare no conflict of interest.

\section{References}

1. Gilja, V.; Novakovic, K.; Travas-Sejdic, J.; Hrnjak-Murgic, Z.; Rokovic, M.K.; Zic, M. Stability and synergistic effect of polyaniline/ $\mathrm{TiO}_{2}$ photocatalysts in degradation of Azo Dye in wastewater. Nanomaterials 2018, 8, 30. [CrossRef] [PubMed]

2. Liao, T.W.; Verbruggen, S.W.; Claes, N.; Yadav, A.; Grandjean, D.; Bals, S.; Lievens, P. TiO 2 films modified with Au nanoclusters as self-cleaning surfaces under visible light. Nanomaterials 2018, 8, 30. [CrossRef] [PubMed]

3. Ye, L.Q.; Su, Y.R.; Jin, X.L.; Xie, H.Q.; Zhang, C. Recent advances in BiOX (X = Cl, Br and I) photocatalysts: Synthesis, modification, facet effects and mechanisms. Environ. Sci. Nano 2014, 1, 90-112. [CrossRef]

4. Liu, S.-H.; Syu, H.-R. One-step fabrication of $\mathrm{N}$-doped mesoporous $\mathrm{TiO}_{2}$ nanoparticles by self-assembly for photocatalytic water splitting under visible light. Appl. Energy 2012, 100, 48-154. [CrossRef]

5. Pang, D.D.; Wang, Y.T.; Ma, X.D.; Ouyang, F. Fluorine promoted and silica supported $\mathrm{TiO}_{2}$ for photocatalytic decomposition of acrylonitrile under simulant solar light irradiation. Chem. Eng. J. 2014, 258, 43-50. [CrossRef]

6. Liu, S.-H.; Syu, H.-R. High visible-light photocatalytic hydrogen evolution of C,N-codoped mesoporous $\mathrm{TiO}_{2}$ nanoparticles prepared via an ionic-liquid template approach. Int. J. Hydrogen Energy 2013, 38, 13856-13865. [CrossRef]

7. Song, X.L.; Li, Y.Y.; Wei, Z.D.; Ye, S.Y.; Dionysiou, D.D. Synthesis of $\mathrm{BiVO}_{4} / \mathrm{P} 25$ composites for the photocatalytic degradation of ethylene under visible light. Chem. Eng. J. 2017, 314, 443-452. [CrossRef]

8. Liu, Y.Z.; Xu, J.A.; Wang, L.Q.; Zhang, H.Y.; Xu, P.; Duan, X.G.; Sun, H.Q.; Wang, S.B. Three-dDimensional $\mathrm{BiOI} / \mathrm{BiOX}(\mathrm{X}=\mathrm{Cl}$ or $\mathrm{Br})$ nanohybrids for enhanced visible-light photocatalytic activity. Nanomaterials 2017, 7, 64. [CrossRef] [PubMed]

9. Tian, L.Y.; Rui, Y.L.; Sun, K.L.; Cui, W.Q.; An, W.J. Surface decoration of $\mathrm{ZnWO}_{4}$ nanorods with $\mathrm{Cu}_{2} \mathrm{O}$ nanoparticles to bBuild heterostructure with enhanced photocatalysis. Nanomaterials 2018, 8, 33. [CrossRef] [PubMed] 
10. Kumar, A.; Kumar, A.; Sharma, G.; Al-Muhtaseb, A.H.; Naushad, M.; Ghfar, A.A.; Stadler, F.J. Quaternary magnetic $\mathrm{BiOCl} / \mathrm{g}-\mathrm{C}_{3} \mathrm{~N}_{4} / \mathrm{Cu}_{2} \mathrm{O} / \mathrm{Fe}_{3} \mathrm{O}_{4}$ nano-junction for visible light and solar powered degradation of sulfamethoxazole from aqueous environment. Chem. Eng. J. 2018, 334, 462-478. [CrossRef]

11. Singh, M.; Jampaiah, D.; Kandjani, A.E.; Sabri, Y.M.; Della Gaspera, E.; Reineck, P.; Judd, M.; Langley, J.; Cox, N.; van Embden, J.; et al. Oxygen-deficient photostable $\mathrm{Cu}_{2} \mathrm{O}$ for enhanced visible light photocatalytic activity. Nanoscale 2018, 10, 6039-6050. [CrossRef] [PubMed]

12. Sakar, M.; Balakumar, S. Reverse Ostwald ripening process induced dispersion of $\mathrm{Cu}_{2} \mathrm{O}$ nanoparticles in silver-matrix and their interfacial mechanism mediated sunlight driven photocatalytic properties. J. Photochem. Photobiol. A 2018, 356, 150-158. [CrossRef]

13. Wei, Q.; Wang, Y.; Qin, H.Y.; Wu, J.M.; Lu, Y.F.; Chi, H.Z.; Yang, F.; Zhou, B.; Yu, H.L.; Liu, J.B. Construction of rGO wrapping octahedral $\mathrm{Ag}-\mathrm{Cu}_{2} \mathrm{O}$ heterostructure for enhanced visible light photocatalytic activity. Appl. Catal. B Environ. 2018, 227, 132-144. [CrossRef]

14. Su, Y.; Li, H.F.; Ma, H.B.; Wang, H.; Robertson, J.; Nathan, A. Dye-assisted transformation of $\mathrm{Cu}_{2} \mathrm{O}$ nanocrystals to amorphous $\mathrm{Cu}_{\mathrm{x}} \mathrm{O}$ nanoflakes for enhanced photocatalytic performance. ACS Omega 2018, 3, 1939-1945. [CrossRef]

15. Sun, S.D. Recent advances in hybrid $\mathrm{Cu}_{2} \mathrm{O}$-based heterogeneous nanostructures. Nanoscale 2015, 7, 10850-10882. [CrossRef] [PubMed]

16. Chen, X.Q.; Wu, Z.S.; Gao, Z.Z.; Ye, B.C. Effect of different activated carbon as carrier on the photocatalytic activity of Ag-N-ZnO photocatalyst for methyl orange degradation under visible light irradiation. Nanomaterials 2018, 7, 258. [CrossRef] [PubMed]

17. Choi, H.; Shin, D.; Yeo, B.C.; Song, T.; Han, S.S.; Park, N.; Kim, S. Simultaneously controllable doping sites and the activity of a W-N codoped $\mathrm{TiO}_{2}$ photocatalyst. ACS Catal. 2016, 6, 2745-2753. [CrossRef]

18. Luster, E.; Avisar, D.; Horovitz, I.; Lozzi, L.; Baker, M.A.; Grilli, R.; Mamane, H. N-doped $\mathrm{TiO}_{2}$-coated ceramic membrane for carbamazepine degradation in different water qualities. Nanomaterials 2017, 7, 206. [CrossRef] [PubMed]

19. Bailón-García, E.; Elmouwahidi, A.; Álvarez, M.A.; Carrasco-Marín, F.; Pérez-Cadenas, A.F.; Maldonado-Hóda, F.J. New carbon xerogel- $\mathrm{TiO}_{2}$ composites with high performance as visible-light photocatalysts for dye mineralization. Appl. Catal. B Environ. 2017, 201, 29-40. [CrossRef]

20. Klaysri, R.; Ratova, M.; Praserthdam, P.; Kelly, P.J. Deposition of visible light-active C-doped titania films via magnetron sputtering using $\mathrm{CO}_{2}$ as a source of carbon. Nanomaterials 2017, 7, 113. [CrossRef] [PubMed]

21. Nica, I.C.; Stan, M.S.; Dinischiotu, A.; Popa, M.; Chifiriuc, M.C.; Lazar, V.; Pircalabioru, G.G.; Bezirtzoglou, E.; Iordache, O.G.; Varzaru, E.; et al. Innovative self-cleaning and biocompatible polyester textiles nano-decorated with Fe-N-doped titanium dioxide. Nanomaterials 2016, 6, 214. [CrossRef] [PubMed]

22. Reddy, P.A.K.; Reddy, P.V.L.; Kwon, E.; Kim, K.H.; Akter, T.; Kalagara, S. Recent advances in photocatalytic treatment of pollutants in aqueous media. Environ. Int. 2016, 91, 94-103. [CrossRef] [PubMed]

23. Chang, M.L.; Hu, H.W.; Zhang, Y.Y.; Chen, D.C.; Wu, L.P.; Li, X.J. Improving visible light-absorptivity and photoelectric conversion efficiency of a $\mathrm{TiO}_{2}$ nanotube anode film by sensitization with $\mathrm{Bi}_{2} \mathrm{O}_{3}$ Nanoparticles. Nanomaterials 2017, 7, 104. [CrossRef] [PubMed]

24. Singh, R.; Dutta, S. A review on $\mathrm{H}_{2}$ production through photocatalytic reactions using $\mathrm{TiO}_{2} / \mathrm{TiO}_{2}$-assisted catalysts. Fuel 2018, 220, 607-620. [CrossRef]

25. Hu, J.L.; Tu, J.H.; Li, X.Y.; Wang, Z.Y.; Li, Y.; Li, Q.S.; Wang, F.P. Enhanced UV-Visible light photocatalytic activity by constructing appropriate heterostructures between mesopore $\mathrm{TiO}_{2}$ nanospheres and $\mathrm{Sn}_{3} \mathrm{O}_{4}$ nanoparticles. Nanomaterials 2017, 7, 336. [CrossRef] [PubMed]

26. Petronella, F.; Truppi, A.; Ingrosso, C.; Placido, T.; Striccoli, M.; Curri, M.L.; Agostiano, A.; Comparelli, R. Nanocomposite materials for photocatalytic degradation of pollutants. Catal. Today 2017, 281, 85-100. [CrossRef]

27. Huang, W.-C.; Lyu, L.-M.; Yang, Y.-C.; Huang, M.H. Synthesis of $\mathrm{Cu}_{2} \mathrm{O}$ nanocrystals from cubic to rhombic dodecahedral structures and their comparative photocatalytic activity. J. Am. Chem. Soc. 2012, 134, 1261-1267. [CrossRef] [PubMed]

28. Shang, Y.; Guo, L. Facet-controlled synthetic strategy of $\mathrm{Cu}_{2} \mathrm{O}$-based crystals for catalysis and sensing. Adv. Sci. 2015, 2, 1500140. [CrossRef] [PubMed] 
29. Yuan, G.-Z.; Hsia, C.-F.; Lin, Z.-W.; Chiang, C.; Chiang, Y.-W.; Huang, M.H. Highly facet-dependent photocatalytic properties of $\mathrm{Cu}_{2} \mathrm{O}$ crystals established through the formation of Au-decorated $\mathrm{Cu}_{2} \mathrm{O}$ heterostructures. Chem. Eur. J. 2016, 22, 12548-12556. [CrossRef] [PubMed]

30. Chen, D.S.; Yu, W.B.; Deng, Z.; Liu, J.; Jin, J.; Li, Y.; Wu, M.; Chen, L.H.; Su, B.L. Hollow $\mathrm{Cu}_{2} \mathrm{O}$ microspheres with two active $\{111\}$ and $\{110\}$ facets for highly selective adsorption and photodegradation of anionic dye. RSC Adv. 2015, 5, 55520-55526. [CrossRef]

31. Zhang, Y.; Deng, B.; Zhang, T.R.; Gao, D.M.; Xu, A.W. Shape effects of $\mathrm{Cu}_{2} \mathrm{O}$ polyhedral microcrystals on photocatalytic activity. J. Phys. Chem. C 2010, 114, 5073-5079. [CrossRef]

32. Xu, L.; Zhang, F.Y.; Song, X.Y.; Yin, Z.L.; Bu, Y.X. Construction of reduced graphene oxide-supported $\mathrm{Ag}-\mathrm{Cu}_{2} \mathrm{O}$ composites with hierarchical structures for enhanced photocatalytic activities and recyclability. J. Mater. Chem. A 2015, 3, 5923-5933. [CrossRef]

33. Babu, S.G.; Vinoth, R.; Narayana, P.S.; Bahnemann, D.; Neppolian, B.S. Reduced graphene oxide wrapped $\mathrm{Cu}_{2} \mathrm{O}$ supported on $\mathrm{C}_{3} \mathrm{~N}_{4}$ : An efficient visible light responsive semiconductor photocatalyst. APL Mater. 2015, 3, 104415. [CrossRef]

34. Yu, L.; Li, G.J.; Zhang, X.S.; Ba, X.; Shi, G.D.; Li, Y.; Wong, P.K.; Yu, J.C.; Yu, Y. Enhanced activity and stability of carbon-decorated cuprous oxide mesoporous nanorods for $\mathrm{CO}_{2}$ reduction in artificial photosynthesis. ACS Catal. 2016, 6, 6444-6454. [CrossRef]

35. Liu, S.-H.; Wei, Y.-S.; Lu, J.-S. Visible-light-driven photodegradation of sulfamethoxazole and methylene blue by $\mathrm{Cu}_{2} \mathrm{O} / \mathrm{rGO}$ photocatalysts. Chemosphere 2016, 154, 118-123. [CrossRef] [PubMed]

36. Upadhyay, R.K.; Soin, N.; Roy, S.S. Role of graphene/metal oxide composites as photocatalysts, adsorbents and disinfectants in water treatment: A review. RSC Adv. 2014, 4, 3823-3851. [CrossRef]

37. Stoller, M.D.; Park, S.; Zhu, Y.; An, J.; Ruoff, R.S. Graphene-based ultracapacitors. Nano Lett. 2008, 8, 3498-3502. [CrossRef] [PubMed]

38. Mayorov, A.S.; Gorbachev, R.V.; Morozov, S.V.; Britnell, L.; Jalil, R.; Ponomarenko, L.A.; Blake, P.; Novoselov, K.S.; Watanabe, K.; Taniguchi, T.; et al. Micrometer-scale ballistic transport in encapsulated graphene at room temperature. Nano Lett. 2011, 11, 2396-2399. [CrossRef] [PubMed]

39. Chen, Y.; Sun, H.Q.; Peng, W.C. 2D transition metal dichalcogenides and graphene-based ternary composites for photocatalytic hydrogen evolution and pollutants degradation. Nanomaterials 2017, 7, 62. [CrossRef] [PubMed]

40. Tian, Y.; Sun, Z.H.; Zhang, Y.G.; Wang, X.; Bakenov, Z.; Yin, F.X. Micro-spherical sulfur/graphene oxide composite via spray drying for high performance lithium sulfur batteries. Nanomaterials 2018, 8, 50. [CrossRef] [PubMed]

41. Gong, Y.X.; Wang, Y.; Sun, G.; Jia, T.K.; Jia, L.; Zhang, F.M.; Lin, L.; Zhang, B.Q.; Cao, J.L.; Zhang, Z.Y. Carbon nitride decorated ball-flower like $\mathrm{Co}_{3} \mathrm{O}_{4}$ hybrid composite: Hydrothermal synthesis and ethanol gas sensing application. Nanomaterials 2018, 8, 132. [CrossRef] [PubMed]

42. Zhou, Y.X.; Jia, L.P.; Wang, T.X.; Du, Y.L.; Wang, C.M. Preparation of carbon nanotube and graphene doped polyphenylene sulfide flexible film electrodes and the electrodeposition of $\mathrm{Cu}_{2} \mathrm{O}$ nanocrystals for hydrogen-generation. Int. J. Hydrogen Energy 2018, 43, 7356-7365. [CrossRef]

43. Sharma, K.; Maiti, K.; Kim, N.H.; Hui, D.; Lee, J.H. Green synthesis of glucose-reduced graphene oxide supported $\mathrm{Ag}-\mathrm{Cu}_{2} \mathrm{O}$ nanocomposites for the enhanced visible-light photocatalytic activity. Compos. Part $B$ 2018, 138, 35-44. [CrossRef]

44. González, J.A.; Villanueva, M.E.; Piehl, L.L.; Copello, G.J. Development of a chitin/graphene oxide hybrid composite for the removal of pollutant dyes: Adsorption and desorption study. Chem. Eng. J. 2015, 280, 42-48. [CrossRef]

45. Stankovich, S.; Dikin, D.A.; Piner, R.D.; Kohlhaas, K.A.; Kleinhammes, A.; Jia, Y.; Wu, Y.; Nguyen, S.T.; Ruoff, R.S. Synthesis of graphene-based nanosheets via chemical reduction of exfoliated graphite oxide. Carbon 2007, 45, 1558-1565. [CrossRef]

46. Liu, S.-H.; Yang, S.-W. Highly efficient cuprous oxide nanocrystals assisted with graphene for decolorization using visible light. Water Air Soil Pollut. 2018, 229, 67. [CrossRef]

47. Pu, Y.-C.; Chou, H.-Y.; Kuo, W.-S.; Wei, K.-H.; Hsu, Y.-J. Interfacial charge carrier dynamics of cuprous oxide-reduced graphene oxide $\left(\mathrm{Cu}_{2} \mathrm{O}-\mathrm{rGO}\right)$ nanoheterostructures and their related visible-light-driven photocatalysis. Appl. Catal. B Environ. 2017, 204, 21-32. [CrossRef] 
48. Gao, Z.; Liu, J.; Xu, F.; Wu, D.; Wu, Z.; Jiang, K. One-pot synthesis of graphene-cuprous oxide composite with enhanced photocatalytic activity. Solid State Sci. 2012, 14, 276-280. [CrossRef]

49. Chang, X.F.; Gondal, M.A.; Al-Saadi, A.A.; Ali, M.A.; Shen, H.; Zhou, Q.; Zhang, J.; Du, M.; Liu, Y.; Ji, G. Photodegradation of Rhodamine B over unexcited semiconductor compounds of $\mathrm{BiOCl}$ and BiOBr. J. Colloid Interface Sci. 2012, 377, 291-298. [CrossRef] [PubMed]

50. Wang, J.T.W.; Ball, J.M.; Barea, E.M.; Abate, A.; Alexander-Webber, J.A.; Huang, J.; Saliba, M.; Mora-Sero, I.; Bisquert, J.; Snaith, H.J.; et al. Low-temperature processed electron collection layers of graphene/ $/ \mathrm{TiO}_{2}$ nanocomposites in thin film perovskite solar cells. Nano Lett. 2014, 14, 724-730. [CrossRef] [PubMed]

51. Yan, S.C.; Li, Z.S.; Zou, Z.G. Photodegradation of Rhodamine B and methyl orange over boron-doped g- $\mathrm{C}_{3} \mathrm{~N}_{4}$ under visible light irradiation. Langmuir 2010, 26, 3894-3901. [CrossRef] [PubMed]

52. $\mathrm{Hu}, \mathrm{X}$; Zhou, X.; Wang, R.; Hu, C.; Qu, J. Characterization and photostability of $\mathrm{Cu} \mathrm{u}_{2} \mathrm{O}-\mathrm{Ag}-\mathrm{AgBr} / \mathrm{Al}_{2} \mathrm{O}_{3}$ for the degradation of toxic pollutants with visible-light irradiation. Appl. Catal. B 2014, 154-155, 44-50. [CrossRef]

(C) 2018 by the authors. Licensee MDPI, Basel, Switzerland. This article is an open access article distributed under the terms and conditions of the Creative Commons Attribution (CC BY) license (http:/ / creativecommons.org/licenses/by/4.0/). 